\title{
MUSICAL IDENTITY OF PATIENTS WITH MULTIPLE SCLEROSIS
}

\author{
Shirlene Vianna Moreira', Cecilia Cavalieri França², \\ Marcos Aurélio Moreira', Marco Aurélio Lana-Peixoto'
}

\begin{abstract}
Musical autobiographies consist of a powerful therapeutic tool by which individuals define themselves. The use of this technique may help (re)construction personal identities and improve quality of life of patients with multiple sclerosis (MS). Eight adult patients on treatment at CIEM Multiple Sclerosis Investigation Center after selecting 10 to 15 pieces of music most significant in their lives were interviewed. The data collected were classified according to Even Rudd categories, which reveal how a person expresses his personal, social, temporal and transpersonal identities. We observed that recall of musical history makes MS patients get better perception both of their feelings and body awareness, as well as provide them with an alternative way to express themselves, activate and contextualize affective memories, and achieving a sense of life continuity in spite of the disease.
\end{abstract}

KEY WORDS: music therapy, multiple sclerosis, musical autobiography, quality of life.

\section{Identidade musical em pacientes com esclerose múltipla}

\begin{abstract}
Resumo - Autobiografias musicais constituem um recurso terapêutico pelo qual indivíduos definem a si mesmos, auxiliando a (re)construção da identidade e contribuindo para a melhora da qualidade de vida de portadores de esclerose múltipla (EM). Oito pacientes adultos sob acompanhamento no Centro de Investigação em esclerose múltipla (CIEM) da UFMG, selecionaram entre 10 e 15 músicas significativas em sua vida, a respeito das quais discorreram em entrevista aberta. Os dados foram analisados qualitativamente segundo categorias criadas por Even Rudd, que visam revelar como o indivíduo expressa suas identidades pessoal, social, temporal e transpessoal. Submetidos a tratamento quantitativo, os dados demonstraram que, através da sua história musical, os pacientes aumentaram a percepção dos sentimentos e sensações corporais, expressaramse de maneiras alternativas e ativaram memórias afetivas, contextualizando-as e adquirindo um senso de continuidade da vida.
\end{abstract}

PALAVRAS-CHAVE: musicoterapia, esclerose múltipla, autobiografia musical, qualidade de vida.

Multiple sclerosis (MS) is the most common chronic disabling disease of the central nervous system in young adults. It is primarily characterized by multicentric inflammation and demyelination, but the role of axonal injury and gliosis increases as the disease evolves ${ }^{1}$. Emotional changes related to MS may encompass a wide variety of phenomena, including anxiety, grief, depression, emotional lability, and euphoria. Like the physical symptoms of MS, these changes may disrupt everyday activities and compromise quality of life ${ }^{2}$. The way each individual emotionally responds to the changes due to MS leads to fundamental changes in his "self" and "identity" nitive and physical changes alter the way a person perceives himself or herself and how he or she evolves un- derstands and interacts with the physical and social environment. Chronic diseases, such as MS, may lead to biographical rupture in patients' life with impact on the physical, socio-economic and temporal spheres ${ }^{4}$.

The concept of identity in contemporary theory emphasizes the experiences lived by individuals ${ }^{5}$. Personal identity is perceived in a dynamic vision of the self in opposition to a relative immutability. Identity is continuously formed and transformed, and it is defined historically and not biologically ${ }^{4}$. Therefore, identity is continuously reconstructed, analyzed and "renegotiated", according to experiences in a social context ${ }^{6}$. The autobiographical narratives through music permit memories of significant events, anxieties, fears and doubts that frequently come

${ }^{1}$ CIEM Multiple Sclerosis Investigation Center, Federal University of Minas Gerais Medical School, Belo Horizonte MG, Brazil; ${ }^{2}$ Department of Musics, Federal University of Minas Gerais, Belo Horizonte MG, Brazil.

Received 30 June 2008, received in final form 10 October 2008. Accepted 20 November 2008. 
along with the disease and perceived in a non-threatening environment. Music works therefore, as patients bank of memory. To study identity means to investigate the ways individuals use to present themselves discursively. The process of identity construction is dynamic and may vary according to the phase of a person's life. Since music is part of our everyday lives, it may structure and anchor a number of different situations when it is used as a raw material in the process of identity construction?

The aim of the study was to describe the process of identity of patients with MS, at a given moment of their lives, through analysis of their musical autobiography report.

\section{METHOD}

Patients from CIEM Multiple Sclerosis Investigation Center, Federal University of Minas Gerais, Belo Horizonte, Brazil, fulfilling criteria for MS according to McDonald et al. ${ }^{8}$ criteria were randomly selected following approval of the study by the Ethical Committee on Research of the Federal University of Minas Gerais. All MS patients were enrolled between June 2006 and December 2006 and signed a Free Consent Agreement Form. Exclusion criteria consisted of evidence of severe comorbidities such as conditions causing respiratory or cardiac insufficiency or psychiatric and cognitive disorders.

The clinical course of the disease was classified according Lublin et al. ${ }^{9}$ criteria and patients' disability scores were assessed by the Kurtzke's Expanded Disability Status Scale (EDSS) ${ }^{10}$.

\section{Procedure}

The patients were submitted to a music therapy questionnaire, comprising their epidemiologic and musical data". They selected 10 to 15 pieces of music most significant in their lives and were then submitted to an open interview, during which they described their experiences and preferences. The collected data were classified according to Rudd's categories ${ }^{7}$, which reveal how the person expresses his personal, social, temporal and transpersonal identities: (1) personal identity, which is related to individual and personal aspects; (2) social identity which refers to interpersonal aspects of identity; (3) temporal identity which refers to the geographic space and time the person feels connected to; (4) transpersonal identity which is related to musical experiences that are beyond language producing altered states of consciousness.

\section{Statistical analysis}

The analysis of the results was focused on studies of personal discourse connected to musical identity. It was carried out through the technique of content analysis ${ }^{12}$ using the categories of identity as described by Rudd ${ }^{7}$. The characterization in categories was interpreted according to socialcultural aspects of the patients. After data analysis, the results of the most relevant categories of the study of musical identity were presented to every interviewed patient.

In order to compare the proportions of each group, confidence intervals of $95 \%$ were set for these proportions. In order to correlate the frequency of each instance with the whole group, the Chi-square test of Pearson was used. Fisher's exact test was used for comparisons between low frequency groups. Windows EPI-INFO was used for statistical analysis and the $5 \%$ level of significance was adopted.

\section{RESULTS}

The sample consisted of eight patients (five men and three women) with ages ranging from 22 to 58 years (mean 44 years). Six patients had relapsing-remitting MS, one had primary-progressive MS, and one had secondary-progressive MS. Patients' EDSS scores ranged from 0 to 5.0 (mean $2.0 \pm 1.8$ ) disease duration varied from 2 to 34 years (mean 14.5 years \pm 12.6$)$.

Table 1. Comparison between the incidences (in percentage) in each category of musical identity of the patients with multiple sclerosis.

\begin{tabular}{|c|c|c|c|c|}
\hline \multirow[t]{2}{*}{ Patients } & \multicolumn{4}{|c|}{ Categories } \\
\hline & Personal & Social & Temporal & Transpersonal \\
\hline 1 & $30(0.13)^{\star}$ & $30(0.49)^{*}$ & $40(0.22)^{*}$ & $0(0.99)^{\star *}$ \\
\hline 2 & $38(0.78)^{\star}$ & $31(0.55)^{\star}$ & $27(0.63)^{*}$ & $4(0.42)^{\star \star}$ \\
\hline 3 & $41(0.69)^{*}$ & $17(0.12)^{\star}$ & $39(0.19)^{*}$ & $3(0.64)^{\star *}$ \\
\hline 4 & $17(0.01)^{*}$ & $30(0.59)^{*}$ & $53(0.01)^{*}$ & $0(0.58)^{\star *}$ \\
\hline 5 & $53(0.11)^{\star}$ & $22(0.64)^{*}$ & $22(0.2)^{*}$ & $2(0.99)^{\star *}$ \\
\hline 6 & $32(0.22)^{*}$ & $53(<0.01)^{*}$ & $15(0.02)^{\star}$ & $0(0.99)^{\star *}$ \\
\hline 7 & $47(0.38)^{\star}$ & $21(0.47)^{*}$ & $32(0.98)^{*}$ & $0(0.6)^{\star *}$ \\
\hline 8 & $64(0.01)^{*}$ & $5(<0.01)^{*}$ & $23(0.28)^{\star}$ & $8(0.06)^{\star *}$ \\
\hline Overall & 41 & 25 & 31 & 2 \\
\hline
\end{tabular}

The results are presented in percentage. *Results of $p$ value (in parentheses) from Chi-square test of Pearson;

**Results from Fisher's test. Note: The $p$ value accepted for detecting differences was $p \leq 0.05$. 
Table 2. Description of incidences in each category of musical identity in patients with multiple sclerosis.

\begin{tabular}{lcc}
\hline Categories & Incidence (\%) & Cl 95\% \\
\hline Personal & $152(41)$ & {$[36 \% ; 45 \%]$} \\
Social & $94(25)$ & {$[21 \% ; 30 \%]$} \\
Temporal & $116(31)$ & {$[27 \% ; 36 \%]$} \\
Transpersonal & $07(2)$ & {$[1 \% ; 4 \%]$} \\
Total & $369(100)$ & \\
\hline
\end{tabular}

$\mathrm{Cl}$, confidence intervals.

Analysis showed that there was a higher frequency of the category personal, suggesting that individual aspects, such as, emotional consciousness, body consciousness, first relations, among others, were clearly reported as patients' memories (Table 1). Confidence intervals analysis shows that there is significant difference between the category transpersonal and the others (Table 2; Figure).

\section{DISCUSSION}

This is a pilot study with a small number of patients recruited from a single MS Center. In spite of that, to the best of our knowledge, it is the first study to investigate musical identity in MS patients. It analyzed neither the musical structure nor the lyrics of the songs chosen by the patients. It focused on the discourse of patients about their personal history rather than the evaluation of the therapeutic effects of listening to the songs from their musical autobiographies. However, significant changes in patients' mood could be easily observed following the interview.

At present time no standard scale to evaluate the identity of the subject or its changes is available. Therefore, we used a qualitative methodology, which has proven to be quite productive in the construction of meanings, values and life histories ${ }^{7}$. Methodology and approach were quite consistent in the study. We recommend further research to study the effect of musics on the quality of life and patients' mood with MS submitted to music-therapeutic interventions.

The study revealed that musics can assist patients to rescue their identity. Feelings and musical preferences do not change in the course of the disease. Music autobiography recall may activate affective memories, increase feeling perceptions and body sensation, increase understanding of the self and arise emotional consciousness. It can help individuals to express themselves in different ways, contextualize time and place of past events in individual's remembrances, provide perception of a continuity of life and relevance of social relations and cultural influences.

Musics can have a supportive role in relation to the history of the individual, working as an anchor at moments

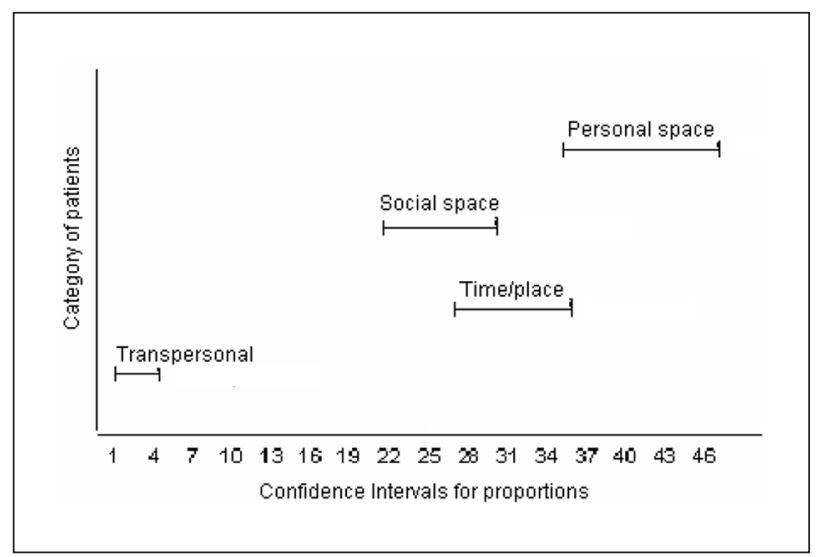

Figure. Confidence Intervals for the proportions in each category of patients

when it is difficult to express feelings through words. In this context, the therapist, based on the history of the patient musical life, can make possible new arrangements for the self. The role of musical culture in personal identity is of utmost importance for the music-therapist concerns. The patients' musical histories presented in their autobiographies might contain relevant issues related to their identities ${ }^{13}$.

By speaking human beings assert their own identities and the subjective beings they wish to be, making themselves effective as subjects. Past conditionings open new windows for the present and future, and subjective beings are strongly influenced by a network of relationships inserted within a specific social and cultural context ${ }^{4}$.

This is quite evident in the musical autobiographies of people affected by MS. Emotional consciousness was reported by patients in the personal category. These emotional exercises can help patients to clarify the emotions, better understand the world around them and, consequently, understand themselves.

In the category social, the data showed that the songs helped the patients to remember the importance of the relationship with others in the course of their lives. As we live in a social world most of the time music is shared by others. Social relationships are of vital importance for one's quality of life.

As the category temporal is concerned, musical experiences brought important remembrances of life events. The remembrance of a time lived or a historical period was emphasized. These events are fixed in the memory, making possible the coherence and continuity of life.

The present study suggests that music therapy can be considered as a potential integrative treatment strategy for patients with MS. There are two main reasons for that. First, because it improves communicative performance 
and promotes presentation of the self. Second, because it may provide patients with a chronic and degenerative disease such as MS with strategies to face the condition with an identity beyond that imposed by the characteristics of a chronic disabling disease ${ }^{14}$. Through music MS patients may write their autobiography bringing to light experiences from different times in the course of their lives.

\section{REFERENCES}

1. Confavreux C, Vukusic S, Moreau T, Adeleine P. Relapses and progression of disability in multiple sclerosis. N Engl J Med 2000;343:1430-1438.

2. Foley FW, Dince WM, LaRocca NG, et al. Psychoremediation of communication skills for cognitively impaired persons with multiple sclerosis. J Neuro Rehab 1994;8:165-176.

3. Magee Wl, Davidson JW. The effect of music therapy on mood states in neurological patients: a pilot study. J Music Ther 2002;39:20-29.

4. Silva LL. Ameaça de identidade e permanência da pessoa: um estudo de sociologia da doença. São Paulo: Cortez, 2004.
5. Hall, SA. Identidade cultural na pós-modernidade, Rio de Janeiro: DP\&AA, 2005

6. Berger P, Berger B, Kellner H. Un mundo sin hogar: modernización y consciência. Santander: Sal Terrae, 1979.

7. Ruud E. Music therapy: improvisation. Communication, and culture Gilsum: Barcelona Publishers, 1998.

8. McDonald WI, Compston A, Edan G, et al. Recommend diagnostic criteria for multiple sclerosis: guidelines from the International Panel in the diagnosis of multiple sclerosis. Ann Neurol 2001;50:121-127.

9. Lublin FD, Reingold SC. Defining the clinical course of multiple sclerosis: results of an international survey. Neurology 1996;46:907-911.

10. Kurtzke JF. Rating neurologic impairment in multiple sclerosis: an expanded disability status scale (EDSS). Neurology 1983;33:144-152.

11. Vianna S, Moreira MA, Haase VG, Lana-Peixoto MA. Music therapy in neurological rehabilitation: a standardized protocol for patients with multiple sclerosis. Arq Neuropsiquiatr 2004;62(Suppl 1):S32.

12. Laville C, Dione J. A construção do saber: Manual de metodologia da pesquisa em ciências humanas. Porto Alegre: Artmed, 1999.

13. Hargreaves D, Miell D, Macdonald R. What are musical identities, and why are they important? In: Macdonald R, Hargreaves D, Miell D (Eds) Musical Identities. New York: Oxford, 2004:1-19.

14. Schmid W, Aldridge D. Active music therapy in the treatment of multiple sclerosis patients: a matched control study. J Music Ther 2004;41: 225-240. 